\title{
Sebastião Soares de Faria
}

Nasceu na cidade de Pinheiros, comarca de Queluz, neste Estado, em 29 de Agosto de 1883. Fez os seus estudos de preparatorios no Collegio Avila, em Espirito Santo do Pinhal, e Collegio "Nogueira da Gama”, em Jacarehy, matriculando-se em 1899 na Escola Polytechnica de São Paulo. Não tendo seguido o curso de engenharia, dedicou-se ao jornalismo, tendo trabalhado em jornaes desta Capital e de Santos. Em 1902, entrou para o corpo docente do Gymnasio "Nogueira da Gama", que foi um dos estabelecimentos de ensino mais afamados do Brasil, tendo leccionado nesse Gymnasio, durante nove annos, quasi todas as disciplinas do curso gymnasial. Matriculou-se na Faculdade Livre de Direito do Rio de Janeiro em 1907, tendo alli feito os tres primeiros annos do curso. Em 1909, transferiu a sua residencia para esta Capital, dedicando-se inteiramente ao magisterio particular, secundario e superior, como repetidor. Fez o quarto e o quinto anno do curso juridico nesta Faculdade, tendo recebido o grau de bacharel em dezembro de 1911. Como representante do Gymnasio "Nogueira da Gama", tomou parte no Congresso de Ensino que se realizou, em 1907, no Rio de Janeiro, tendo apresentado um trabalho sobre a reforma do ensino, que teve muitas de suas conclusões aprovadas. Foi professor de Economia Politica e Encyclopedia Juridica na Faculdade de Direito da extinta Universidade de São Paulo, tomando parte no curso de conferencias desse Instituto, falando, entre outros assumptos, sobre "Um novo Conceito do Direito Natural", "Leis Fundamentaes da Economia Politica" e "O Ensino do Patrio- 
tismo" Logo depois de formado, abandonou o ensino para dedicar-se exclusivamente á advocacia commercial. Em agosto de 1933, fez concurso para o cargo de lente cathedratico de Direito Commercial, tendo sido habilitado, sendo nomeado livre docente dessa materia. Em consequencia, recebeu o grau de doutor em 10 de dezembro do corrente anno. E' lente cathedratico de "Direito Commercial Internacional", na Faculdade de Sciencias Economicas desta Capital, membro do Instituto dos Advogados, e do Conselho da Ordem dos Advogados do Brasil, secção de São Paulo.

\section{OBRAS PUBLICADAS:}

O Ensino da Historia Universal - Prelecção inaugural - Jacarehy -1905 .

o Ensino Secundario e a sua reforma - Memorial apresentado ao Congresso de Ensino - Jacarehy - 1907.

Investigaçẫo da Paternidade Illegitima - 1." edição - Saraiva \& Cia. - 1917.

Investigações da Patternidade Illegitima - 2." edição - Saraiva \& Cia. - 1926.

Da Concordata Terminativa - Saraiva \& Cia. - 1927.

Da Concordata Preventiva - Saraiva \& Cia. - 1931.

Do Abuso da Razão Social - These de concurso - Saraiva \& Cia. - 1933.

Pareceres e Commentarios - Trabalhos de Direito Commercial "Rev. dos Tribunaes" - 1933.

Da Exclusão dos Socios nas Sociedades de Responsabilidade Limitada - Saraiva \& Cia. - 1926. 